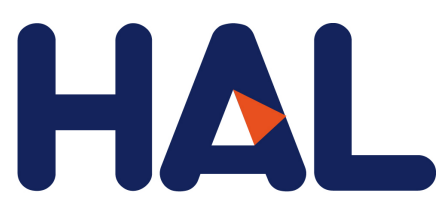

archives-ouvertes

\title{
The historical development of inverse marking in Khroskyabs: evidence from two modern varieties: Siyuewu and Wobzi
}

\author{
Lai Yunfan
}

\section{- To cite this version:}

Lai Yunfan. The historical development of inverse marking in Khroskyabs: evidence from two modern varieties: Siyuewu and Wobzi. 2019. halshs-02266342

\section{HAL Id: halshs-02266342 https://halshs.archives-ouvertes.fr/halshs-02266342}

Submitted on 14 Aug 2019

HAL is a multi-disciplinary open access archive for the deposit and dissemination of scientific research documents, whether they are published or not. The documents may come from teaching and research institutions in France or abroad, or from public or private research centers.
L'archive ouverte pluridisciplinaire HAL, est destinée au dépôt et à la diffusion de documents scientifiques de niveau recherche, publiés ou non, émanant des établissements d'enseignement et de recherche français ou étrangers, des laboratoires publics ou privés. 


\title{
The historical development of inverse marking in Khroskyabs: evidence from two modern varieties: Siyuewu and Wobzi ${ }^{12}$
}

\author{
Lai Yunfan \\ Max-Planck-Institut für Menschheitsgeschichte
}

This paper describes the inverse marking systems of two closely related Khroskyabs varieties, Siyuewu and Wobzi, and hypothesises the historical development of the Khroskyabs inverse marking system. I propose that a hypothetical prefix, ${ }^{*}$ Co-, which is probably related to the second person markers attested in many Trans-Himalayan languages, existed in Proto-Khroskyabs, and that it has different reflexes in the two modern Khroskyabs varieties.

Key words: Khroskyabs, Rgyalrongic, argument indexation, inverse marking, second person prefix

\section{Introduction}

Inverse marking is a type of argument indexation first discovered in Algonquian languages (Plains Cree, for example, see Wolfart 1973). Although there are some exceptions (Jacques \& Antonov 2014: 311), it occurs generally in transitive constructions of head-marking languages, to mark the inverse relation between the A and the $\mathrm{P}$, where the A ranks lower than the $\mathrm{P}$ in the empathy hierarchy (DeLancey 1981). For instance, in Plains Cree, the morpheme -iko in (1b) marks the inverse direction, as the A (third person plural) ranks lower than the $\mathrm{P}$ (first person plural) in the empathy hierarchy.

(1) Plains Cree (Klaiman 1992: 230, Wolfart \& Carroll 1981: 69)

a. Ni-pēh-ā-nān-ak

1-wait-DIR-1PL-3PL

'We await them.'

b. Ni-pēh-iko-nān-ak

1-wait-INV-1PL-3PL

'They await us.'

This paper describes the inverse marking system in Khroskyabs, with special focus on the Siyuewu and the Wobzi varieties and carries out a hypothesis on the development of inverse marking in Khroskyabs by comparing the nuances in usage between the two varieties.

The paper is structured as follows: in the next two subsections, I present some background information of Khroskyabs, focusing on its argument indexation. In Section 2, I provide a brief presentation of the inverse marking systems in Rgyalrongic languages in general. In Sections 3 and 4, I make a detailed description of the inverse marking systems of the two Khroskyabs varieties under study, Siyuewu and Wobzi. In Section 5, I postulate a hypothesis on the evolution of inverse marking in Khroskyabs, in order to reconstruct its protosystem. Finally, Section 6 wraps up the paper.

\footnotetext{
${ }^{1}$ I use the Wylie transliteration of Tibetan in this paper (Wylie 1959). I follow the Leipzig Glossing Rules, additional abbreviations are: DIR: directional prefix; INV: inverse, ORIEN: orientational prefix, NVIS: non-visual, CONJ: conjunction, PN: personal name, INTERJ: interjection, TRANS: translocative, IFR: inferential, REPEAT: repetition, DUB: dubitative, POT: potential, $\mathrm{NEG}_{2}$ : negative marker mæ-/main Wobzi that appears only after orientational prefixes, $\mathrm{NEG}_{3}$ : negative marker $m a$ - in Wobzi that appears in the past tense of verbs uncompatible with orientational prefixes, PART: sentence final particle.

${ }^{2}$ This research was supported by the ERC Starting Grant 715618 CALC. I would like to thank Guillaume Jacques, Scott Delancey, Zhang Shuya, Gong Xun and the two anonymous reviewers for their constructive comments and suggestions.
} 


\subsection{The Khroskyabs language}

Khroskyabs is classified under the Rgyalrongic branch in the Trans-Himalayan language family. It forms with the Stau varieties and possibly Tangut (Sagart et al. 2019; Lai et al. manuscript) the West-Rgyalrongic subgroup, as opposed to the other subgroup, the Rgyalrong languages, which comprise Situ, Japhug, Tshobdun and Zbu (Sun 2000a; b; Lai 2017; Gong 2018).

\subsection{Dialects under investigation}

The two varieties discussed in this paper, Siyuewu (斯躍武 Sīyuèwǔ) and Wobzi (俄熱 Érè), are spoken in two different townships, Dzamthang (壤塘縣 Răngtáng Xiàn) and Chuchen (金川縣 Jīnchuān Xiàn) respectively, with a driving distance of 46 kilometres from one to the other. Based on common phonological and lexical innovations, the Stammbaum of Khroskyabs is illustrated in Figure 1 (Lai 2017: 15). Siyuewu and Wobzi are both classified under the Thugschen subgroup.

The two varieties are mostly mutually intelligible to native speakers, but they present subtle yet important differences linguistically.

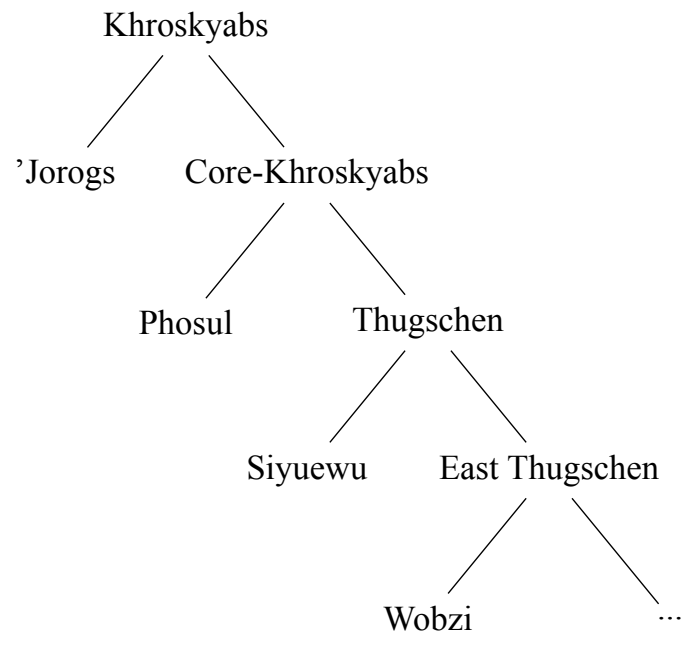

Figure 1. Stammbaum of Khroskyabs according to Lai (2017: 15)

\subsection{Argument indexation}

Since inverse marking is a sub-domain of argument indexation, it is indispensable to give an outline of the argument indexation system in Khroskyabs. Like other Rgyalrongic languages (Jacques 2004; Gong 2018; Zhang 2019), the argument indexation system in Khroskyabs is based on morphological transitivity (Jacques 2012b). Thanks to their different paradigms, two types of verbs can be unamibiguously distinguished in a morphological way. The first type of verbs, called intransitive verbs, index only one argument; and the second type, called transitive verbs, index information of two arguments with personal suffixes as well as inverse marking. Tables (1) and (2) show the intransitive and the transitive paradigms of Siyuewu Khroskyabs. 
Table 1. Intransitive indexation in Siyuewu

\begin{tabular}{|c|c|c|}
\hline & Suffixes & Pronouns \\
\hline $1 \mathrm{sG}$ & $\Sigma-\eta$ & $\eta \hat{\mathfrak{x}}$ \\
\hline $1 \mathrm{DU}$ & $\Sigma-\gamma$ & ggône, yône \\
\hline 1 PL & $\Sigma-j$ & 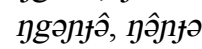 \\
\hline $2 \mathrm{sg}$ & $\sum-n$ & $n \hat{u}$ \\
\hline $2 \mathrm{DU}$ & $\Sigma-z$ & nêne \\
\hline 2PL & $\sum-n$ & nênfo \\
\hline $3 \mathrm{sg}$ & $\Sigma$ & $c \hat{\jmath}, æ t \hat{\jmath}$ \\
\hline $3 \mathrm{DU}$ & $\Sigma$ & cône, ætône \\
\hline 3PL & $\Sigma$ & côfə, ætôfə \\
\hline
\end{tabular}

Table 2. Siyuewu transitive indexation

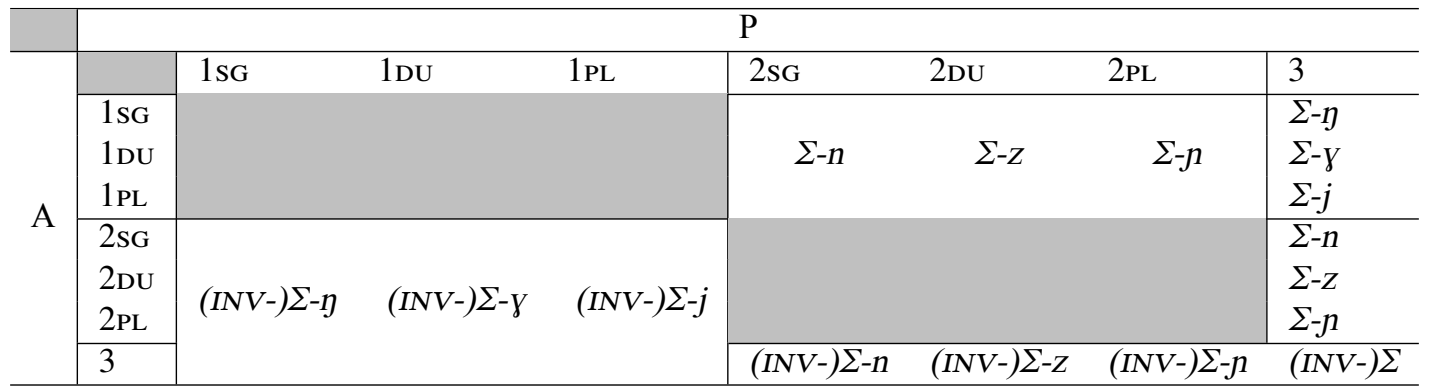

From the perspective of personal suffixes, Siyuewu distinguishes three numbers, singular, dual and plural, for SAP pronouns ${ }^{3}$, and has no number distinction for third person. In the transitive paradigm, Siyuewu exhibits globally a hierarchical alignment, where the suffix is indexed for SAP arguments, see (2a). Within SAP arguments, the $\mathrm{P}$ is indexed, see (2b) and (2c).

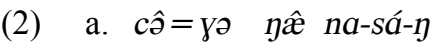
3SG=ERG 1sG PST.INV-kill $2-1$ sG 'He killed me.'

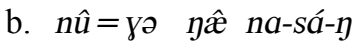
2SG=ERG 1sG PST.INV-kill $2-1 \mathrm{sG}$ 'You killed me.'

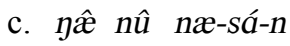

1sG 2sG PST-kill $2-2$ sG

'I killed you.'

Apart from the suffixes, an additional preverbal element occurs in some specific cases, see the prefix difference between Example (2c) (næ-) and the other two examples in (2) (na-). The element $a$ - is exactly the inverse marker that I mainly deal with in this paper.

Lai $(2015$; 2017) accounts for the argument indexation system in the Wobzi variety of Khroskyabs, which is similar to the Siyuewu system. However, Wobzi is simplified suffix-wise: there is no 1Du, only $-\eta$ ' '1sG' and $-j$ ' $1 \mathrm{PL}$ ' are preserved, and the only suffix preserved for second person is $-n$ ' 2 '. The use of the inverse marker in Wobzi presents also some differences from that of Siyuewu.

\footnotetext{
${ }^{3} \mathrm{SAP}=$ speech act participant (first and second persons)
} 


\section{Inverse marking in Rgyalrongic languages}

In this section, I present inverse marking systems in Rgyalrongic languages in general. In Section 2.1, I provide some theoretical background information; in Section 2.2, I focus on inverse marking in Rgyalrong languages and in Section 2.3, I discuss inverse marking in West-Rgyalrongic.

\subsection{Scenarios}

I follow the method proposed by Zúñiga (2006) in my analysis, in which three transitive scenarios are distinguished: local (SAP $\leftrightarrow \mathrm{SAP}$ ), mixed (SAP $\leftrightarrow 3$ ) and non-local $(3 \leftrightarrow 3$ ), each scenario can be further divided into direct and inverse sub-scenarios, according to the language-specific empathy hierarchy.

\subsection{Inverse marking in Rgyalrong languages}

There are at least four recent publications dedicated to inverse marking or argument indexation in Rgyalrong languages: Jacques (2010) for Japhug, Gong (2014) for Zbu, Sun (2015) for Sastod Situ and Zhang (2019) for Bragbar Situ.

Generally, Rgyalrong languages exhibit such an empathy hierarchy: $1>2>3>3$ '. In the local configuration, first person outranks second person; in the mixed configuration, SAP arguments outrank the non-SAP one; and in the non-local configuration, the treatment between 3 and 3' varies from language to language. In Table 3, the generic inverse system in Rgyalrongic languages is illustrated.

Table 3. Generic inverse system in Rgyalrong languages

\begin{tabular}{l|c|c|c|c|c}
\hline \multicolumn{2}{c|}{} & \multicolumn{4}{c}{$\mathrm{P}$} \\
\cline { 3 - 6 } \multicolumn{2}{c|}{} & 1 & 2 & 3 & 3 \\
\hline \multirow{4}{*}{$\mathrm{A}$} & 1 & & & & \\
\cline { 2 - 5 } & 2 & INV & & & \\
\cline { 2 - 5 } & 3 & INV & INV & & \\
\cline { 2 - 5 } & 3 & & & INV & \\
\hline
\end{tabular}

In Zbu, the directions in non-local scenarios are determined by animacy, as illustrated in (3). In (3a), the A of the predicate, tsseci 'Bkrashis (personal name)', is animate, and the P, skutsé? 'stone', is inanimate, therefore the inverse marker does not occur; Example (3b) is the reverse scenario of Example (3a), where the A is inanimate and the $\mathrm{P}$ is animate, in this case, the inverse marker wə- must appear.

(3) Zbu (Gong 2014: 50)

a. $\operatorname{Direct}\left(3 \rightarrow 3^{\prime}\right)$

tseçî ko skutsé? ne-e-tchó $\quad k i$

Bkrashis ERG stone AOR-DIR-Smash 2 NVIS

'Bkrashis smashed a stone.'

b. Inverse $\left(3^{\prime} \rightarrow 3\right)$

tşeçî skutsé? kə to-wə-Xsôv ki

Bkrashis stone ERG AOR-2-INV-hit 2 NVIS

'A stone hit Bkrashis.'

Other Rgyalrong languages may have different distributions for 3 and 3', and some even individually grammaticalised the non-local direct-inverse distinction in various ways. 
The Sastod variety of Situ distinguishes third person singular, which ranks higher, from third person nonsingular (Sun 2015: 733). Therefore, the non-local direct scenario is $3 \mathrm{sG} \rightarrow 3 \mathrm{NS}$, and the non-local inverse scenario is 3NS $\rightarrow$ 3sG. Brag-bar Situ generalised the non-local inverse use to the past tense (Zhang 2019).

\subsection{Inverse marking in West-Rgyalrongic}

Three recent publications specifically focus on the inverse marking or argument indexation in West-Rgyalrongic: Sun \& Tian (2014) for Gexi (Stau), Jacques et al. (2014) for Khang.gsar (Stau) and Lai (2015) for Wobzi Khroskyabs. The system in Tangut, an extinct language that was probably also a West Rgyalrongic language (Lai et al. manuscript), is mentioned in Gong (2017).

Although there are superficial exceptions due to phonotactics and morphology (as will be discussed below), It is believed that West-Rgyalrongic neutralised the contrast between 3 and 3', and generalised the inverse use to all non-local scenarios (Jacques et al. 2014: 89, Lai 2015: 283-284). This neutralisation is also considered one of the shared innovations that characterise the West-Rgyalrongic subgroup. The generic inverse system in West-Rgyalrongic is shown in Table 4.

Table 4. Generic inverse system in West-Rgyalrongic languages

\begin{tabular}{l|c|c|c|c}
\hline \multicolumn{2}{c|}{} & \multicolumn{3}{c}{$\mathrm{P}$} \\
\cline { 3 - 5 } \multicolumn{2}{c|}{} & 1 & 2 & 3 \\
\hline \multirow{3}{*}{$\mathrm{A}$} & 1 & & & \\
\cline { 2 - 5 } & 2 & INV & & \\
\cline { 2 - 5 } & 3 & INV & INV & INV \\
\hline
\end{tabular}

\section{Inverse marking in Siyuewu Khroskyabs}

In this section, I describe the inverse marking in Siyuewu Khroskyabs in detail. I start with the morphophonology in Section 3.1 in order to deal with the conditions of the occurrence of the inverse marker, and give examples in Section 3.2 and Section 3.3 for each condition.

\subsection{Morphophonology}

In Siyuewu Khroskyabs, the inverse marker does not have an independent form and thus cannot appear alone. It has to depend on the orientational prefixes or the negative prefix.

Orientational prefixes have two major functions. First, they indicate the direction of the action denoted by a verb, as shown in (4a) (up) and (4b) (down); and second, they are lexically assigned to verbs to mark TAME ${ }^{4}$ properties, as shown in (4c) (non-past) and (4d) (past). Most verbs are obligatorily prefixed by an orientational marker in the past tense, but there are a handful of verbs that are not compatible with orientational prefixes in such a situation (for example, vdê 'to see', as will be illustrated further below).

(4) Siyuewu Khroskyabs

a. $\eta \hat{x} \quad o-v \hat{o}-\eta$

$1 \mathrm{sG}$ NPST:up-go $1-1 \mathrm{sG}$

'I am going up.'

b. $\eta \hat{\mathfrak{x}} n æ-v \hat{o}-\eta$

1SG NPST:down-go $1-1 \mathrm{sG}$

'I am going down.'

\footnotetext{
${ }^{4}$ TAME is short for tense-aspect-modality-evidentiality.
} 
c. $\eta \hat{x} \quad r ə-d z \hat{\imath}-æ \eta$

1 SG NPST-eat $1-1$ sG

'I am eating/I am going to eat.'

d. $\eta \hat{x} \quad o-d z i ́-æ \eta$

$1 \mathrm{sG}$ PST-eat $2-1 \mathrm{sG}$

'I ate.'

The inverse marker colours the vowel of orientational prefixes with [+back], [+round] or [-high] features, as shown in (5).
(5) a. - - $-\mathrm{INV}>-a([+$ back $])$
b. $-\partial-\operatorname{InV}>-u([+$ round $])$
c. $-O-$ INV $>-a([-$ high $])$

The vowel-colouring results in two series of orientational prefixes, a default series and an inverse series, as shown in Table $5^{5}$.

Table 5. Orientational prefixes in Siyuewu

\begin{tabular}{l|c|c|c|c|c|c|c|c}
\hline & neutral 1 & neutral 2 & up & down & ubac & adret & downstream & upstream \\
\hline Set 1 (default) & $\mathfrak{n}$ & ro- & o- & næ- & kə- & no- & vo- & læ- \\
\hline Set 2 (inverse) & & ru- & $a-$ & na- & ku- & nu- & vu- & la- \\
\hline
\end{tabular}

When there is no orientational prefix, the inverse marker in Siyuewu depends on the negative marker mə- by colouring the vowel into $-u$, as shown in (6).

(6) mo-INV $>$ mu-

\subsection{With orientational prefixes}

In this part, I analyse the use of inverse with orientational prefixes in each scenario. I first provide canonical non-natural examples, then examples from natural narratives ${ }^{6}$.

\subsubsection{Local scenarios}

The canonical examples for local scenarios are illustrated with the verb dzîd 'to eat', of which the past tense goes with the orientational prefix $o$ - 'up'. The local direct scenario is shown in (7a), and the local inverse scenario in $(7 b)$.

(7) Siyuewu Khroskyabs

a. Direct

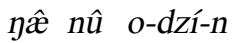

1 SG 2 SG PST-eat 2 -2SG

'I ate you.'

\footnotetext{
${ }^{5}$ The first prefix for neutral orientation, $\mathfrak{x}$-, is never attested with the inverse marker.

${ }^{6}$ I provide the identification number of each natural example. The reader is invited to contact me for primary data.
} 
b. Inverse

$n \hat{u}=$ yə $\eta \hat{x} \quad a-d z i ́-æ \eta$

$2 \mathrm{SG}=\mathrm{ERG} 1 \mathrm{SG}$ PST.INV-eat 2 -1sG

'You ate me.'

Natural examples are shown in (8). Example (8a) shows a local direct scenario with the verb ncô 'to throw', and Example (8b) shows a local inverse scenario, with the verb nvlú 'to fool'.

In narratives, it is usual that personal pronouns are omitted, as in (8a), where the A, $\eta \hat{x}$ ' $1 \mathrm{sg}^{\mathrm{s}}$ ', is not pronounced but can be inferred from the context. The inflected verb form næ-ncó-n (РST-throw 2 -2sG), with the uncoloured orientational prefix $n æ-$, and the suffix $-n$ ' $2 \mathrm{sg}$ ', can only imply a local direct scenario.

In (8b), the inflected verb form na-nvlû- $\eta$ (PST.INV-fool $2-1 \mathrm{sG}$ ), with the inverse-coloured orientational prefix $n a$ - and the suffix $-\eta$ ' $1 \mathrm{sG}^{\mathrm{s}}$ ', implies a local or mixed inverse scenario, however the context shows that it can only be a local one.

(8) Siyuewu Khroskyabs

a. Direct

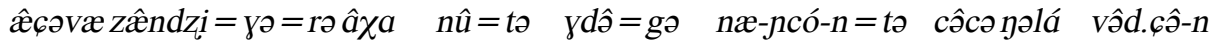

CONJ PN=ERG=TOP INTERJ $2 \mathrm{SG}=$ DEF water=LOC PST-throw 2 -2SG DEM where bring 2 . TRANS $_{2}-2 \mathrm{SG}$

ku-rô rə-nó

PST.INV-Say 2 NPST-be 1

'Then, zêndz̨i said, "Oh, I threw you into the water, where did you bring this from?”' (syw0823)

b. Inverse

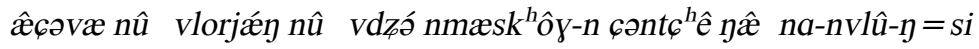

CONJ 2SG PN 2sG mate bully ${ }_{1}-2 \mathrm{sg}$ very $1 \mathrm{SG}$ PST.INV-fool $2-1 \mathrm{sG}=\mathrm{IFR}$

'Then, he said, 'vlorjǽy, you always bully others, you fooled me!”' (syw0703)

\subsubsection{Mixed scenarios}

I use again the verb $d z \hat{i} d$ 'to eat' to illustrate canonical examples of the mixed configuration, see the examples in (9). In (9a), the scenario is $1 \rightarrow 3$ (mixed direct); and in (9b), the scenario is $3 \rightarrow 2$ (mixed inverse).

(9) Siyuewu Khroskyabs

a. Direct

$\eta \hat{x} p^{h}$ ingó $=$ to o-dzí-æy

$1 \mathrm{sG}$ apple $=$ DEF PST-eat $2-1 \mathrm{sG}$

'I ate the apple.'

b. Inverse

$\chi p^{h} r \hat{\jmath}=$ уə nû $a-d z i ́-n$

bear=ERG 2SG PST.INV-eat 2 -2sG

'The bear ate you.'

Natural examples of the mixed configuration are shown in $(10)$. The direct scenario $(3 \rightarrow 2)$ is illustrated with the verb $c^{h} \hat{o}$ 'to open' in $(10 \mathrm{a})$, and the inverse scenario $(3 \rightarrow 1)$ with the verb $n k^{h} \partial k^{h}$ á 'to follow' in $(10 \mathrm{~b})$.

(10) Siyuewu Khroskyabs

a. Direct

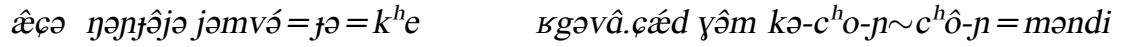

CONJ CONJ family.member $=$ PL=DAT please door IMP-Open $1-2$ PL $\sim$ REPEAT-2PL=unless

'Then, he said to his family members several times, "Please open the door, or..." (syw0419) 
b. Inverse

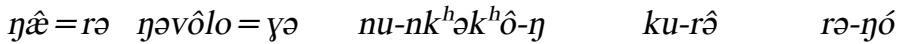

$$
\begin{aligned}
& 1 \mathrm{sG}=\text { TOP old.fellow=ERG PST.INV-follow } 2 \text {-1sG PST.INV-say } 2 \text { NPST-be }{ }_{1} \\
& \text { “'I was followed by that old fellow (the yeti)!” he said.' (syw0419) }
\end{aligned}
$$

\subsubsection{Non-local scenarios}

In non-local scenarios, the inverse marker always appear, as shown in (11). In (11a), the $\mathrm{A}$ is animate and the $\mathrm{P}$ is inanimate; in (11b), the $\mathrm{A}$ is inanimate and the $\mathrm{P}$ is animate.

(11) Siyuewu Khroskyabs

a. $s t \hat{x} b=t ə=$ yə $\chi \varphi \dot{1} \quad a-d z i ́ d=t s^{h_{i}}$

tiger $=$ DEF $=$ ERG grass PST.INV-eat ${ }_{2}=$ IFR

'Oops, the tiger ate the grass.'

b. sæqé= yə ylé nu-scór

stump $=$ ERG rabbit PFV.INV-scare 2

'The stump scared the rabbit.'

Natural examples are shown in (12). In (12a), a 3SG $\rightarrow$ 3PL scenario is shown, the inverse marker appears on the verb form ku-spîd (PST.INv-hide 2 ), the same scenario will render a direct configuration in Sastod Situ. The examples (12b) and (12c) show that animacy is irrelevant to the use of inverse.

(12) Siyuewu Khroskyabs

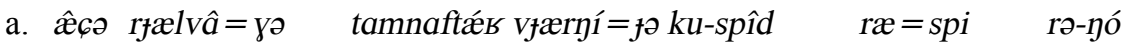
CONJ Big.Monk $=$ ERG whatever yeti $=$ PL PST.INV-hide say $_{1}=$ NMMLZ NPST-be $_{1}$ 'Then it is said that the Big Monk hid all the yetis away.' (syw0468)

b. $b r o ́=t ə=f ə=y ə \quad n a-s l u ́=s i=t ə \quad t^{h} j \hat{x} \quad n æ-\eta \hat{u} \sim \eta u$ horse $=$ DEF $=$ PL $=$ ERG PST.INV- dig $_{2}=$ IFR $=$ DEF what IPFV.PST-be $2 \sim$ be $_{2}$ 'The horses dug them, whatever they were.' (syw1345)

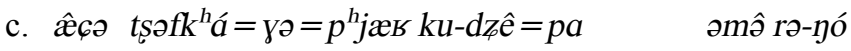
CONJ epilepsy $=$ ERG $=$ TOP $\quad$ PST.INV-hold ${ }_{2}=$ NMLZ DUB NPST-be 2

'It could be that one got epilepsy (literally: epilepsy held the patient).' (syw1393)

\subsection{Without orientational prefixes}

In the absence of an orientational prefix, the inverse marker does not occur unless there is a negative prefix mə-, see (13). In (13a), the verb vdê 'to see' is morphologically incompatible with orientational prefixes in the past tense, even though the scenario is inverse $(3 \rightarrow 1)$, the inverse marker cannot occur without a host; Example (13b) shows a direct scenario $(1 \rightarrow 3)$ with the negative prefix mə-, and in (13c), which exhibits an inverse scenario, the negative prefix mə- serves as the host of the inverse marker, with which it merges into mu-.

(13) Siyuewu Khroskyabs

a. Affirmative

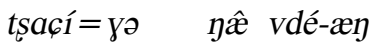

Bkrashis=ERG 1sG see $2-1 \mathrm{sG}$

'Bkrashis saw me.' 
b. Negative (direct)

$\eta \hat{x}$ tsací mə-vdé-æy

1sG Bkrashis=ERG NEG-See $2-1$ sG

'I did not see Bkrashis.'

c. Negative (inverse)

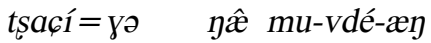

Bkrashis=ERG 1sG NEG.INV-See 2 -1SG

'Bkrashis did not see me.'

In the case where both an orientational prefix and the negative prefix are present, the inverse marker is hosted by the orientational prefix, as shown in (14).

(14) Siyuewu Khroskyabs

tșací= yə $\eta \hat{x}$ ru-mə-vdê-æy

Bkrashis=ERG 1SG NPST.INV-NEG-See 1 -1SG

'Bkrashis will not see me.'

In $3 \rightarrow 3$ scenarios, verbs without orientational prefixes do not exhibit inverse marking in the affirmative case. In the negative case, the inverse marker has fused with the negating prefix, as shown in (15).

(15) Siyuewu Khroskyabs

a. Affirmative

sú= yə $\chi \epsilon \hat{\imath} \quad d z \hat{d} d$

cattle $=$ ERG grass eat 1

'Cattle eat grass.'

b. Negative

sú = yə bjænê mu-dzîd

cattle $=$ ERG meat NEG.INV-eat 1

'Cattle do not eat meat.'

Natural examples are given in (16). In (16a), the inflected verb form s引ǽ $-\eta$ (hang ${ }_{1}=1 \mathrm{sG}$ ) is used in a $2 \rightarrow 1$ scenario, according to the context. However, it allows for multiple interpetations when taken out of the context, due to the non-occurrence of the inverse: $1 \rightarrow 2 / 3,2 / 3 \rightarrow 1$. In (16b), the inflected form mu-gí(NEG.INVwear $_{1}$ ) indicates unamibiguously a $3 \rightarrow 3$ scenario.

(16) Siyuewu Khroskyabs

a. Affirmative

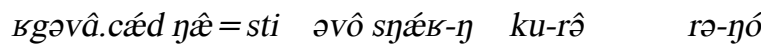

please $\quad 1 \mathrm{sG}=$ time POT hang-1sG PST.INV-Say 2 NPST-be 1

“"Please, hang me!" he said.' (syw0794)

b. Negative

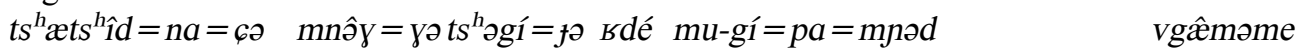

a. while $=$ about $=$ CONJ $\mathrm{red}=$ ERG clothes $=$ PL at.all $\mathrm{NEG} . \mathrm{INV}-$ wear $_{1}=\mathrm{NMLZ}=$ appearance totally.naked

'After a while, a red (woman) that wears no clothes at all, totally naked...' (syw0070)

\section{Inverse marking in Wobzi Khroskyabs}

In this section, I present the inverse marking system in Wobzi Khroskyabs, which is slightly different from the Siyuewu one. However, the difference between the two varieties may contain important information about the history of inverse marking in Khroskyabs, as will be discussed in Section 5. 


\subsection{Morphophonology}

Unlike Siyuewu Khroskyabs, the Wobzi inverse marker seems to have an independent form, $u$-. Synchronically, it does not necessarily need a host to occur. In the presence of an orientational prefix, the inverse marker $u$ - undergoes crasis by replacing the vowel of the orientational prefix, no matter what the vowel is, see Table 6 for a full list of inverse-coloured orientational prefixes. I use a hyphen between the orienational prefix and the inverse marker to account for the fact that the inverse $u$ - is synchronically independent.

Table 6. Orientational prefixes in Wobzi

\begin{tabular}{l|c|c|c|c|c|c|c}
\hline & neutral & up & down & ubac & adret & downstream & upstream \\
\hline Set 1 (default) & rə- & $æ-$ & næ- & kə- & nə- & və- & læ- \\
\hline Set 2 (inverse) & r-u- & $u-$ & $n-u-$ & k-u- & $n-u-$ & v-u- & l-u- \\
\hline
\end{tabular}

The negative prefix in Wobzi cannot serve as the host of the inverse marker, unlike the case of Siyuewu.

\subsection{Distribution}

In this part, I present the distribution of the inverse marker in Wobzi, focusing on its differences from that in Siyuewu.

\subsubsection{With orientational prefixes}

Like Siyuewu, the inverse marker in Wobzi is always present with an orientational prefix in inverse scenarios, see the natural examples in (17). In (17a), the inflected verb form $n$ - $u$-ldzâ- $\eta$ (IMP-INV-teach $\left.{ }_{1}-1 \mathrm{sG}\right)$ is used in a $2 \rightarrow 1$; in $(17 \mathrm{~b})$, the inflected form $1-u-t^{h} \mathfrak{x}-j$ (NPST-INV-take.care $1-1 \mathrm{PL}$ ) is used in a $3 \rightarrow 1$ scenario; in (17c), the inflected form $n-u-r l i \hat{~(P S T-I N V-s k i n} 2)$ is used in a non-local scenario, which is always inverse.

(17) Wobzi Khroskyabs

a. Local inverse

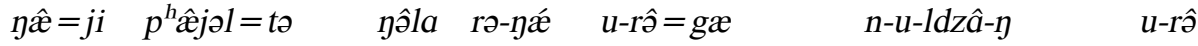
$1 \mathrm{sG}=\mathrm{GEN}$ home.town $=$ DEF where NPST-be ${ }_{1}$ PST.INV-Say ${ }_{2}=\mathrm{CONJ}_{\text {IMP-INV-teach }}-1$ sG PST.INV-say 2 “"Where is my hometown? Tell me!” he said.' (wob0226-0227)

b. Mixed inverse nəjê $=k^{h}$ e $k^{h} \hat{a}-j=s p i \quad$ mí $\quad$ ggône $p^{h} \hat{a} m a=n e k-\hat{a}-d æ-j \quad$ co $\quad l-u-t^{h} \mathfrak{x}-j=p a$ $2 \mathrm{sG}=\mathrm{DAT}$ give $1-1 \mathrm{PL}=$ NMLS not.exist 1 1DU parents $=$ DU NPST-IRR-be.old 1 - 1 PL CONJ NPST-INV-take.care $1-1 \mathrm{PL}=\mathrm{NMLZ}$ mí $\quad u-r \hat{a}=s \hat{\imath}$ not.exist 1 PST.INV-Say $2=$ IFR

"'We can't give (our son) to you. If we do, when we are old, no one will take care of us." said the two.' (wob0366-0367)

c. Non-local $\hat{x} \varphi ə$ ryâvipa $=$ yə $p^{h}$ argê $=$ tə $n-u-r l \hat{\imath}=s i$ CONJ hunter $=$ ERG boar $=$ DEF PST-INV-Skin ${ }_{2}=$ IFR 'Then the hunter skinned the wild boar.' (wob0820) 


\subsubsection{Without orientational prefixes}

While the behaviour of the inverse marker is the same as in Siyuewu in the presence of an orientational prefix, the case without orientational prefixes is different in Wobzi. The inverse marker $u$ - must appear in local and mixed inverse scenarios, and must be absent in non-local scenarios. Canonical examples are shown in (18) with the verb vdê 'to see', which is incompatible with orientational prefixes in the past tense. The inverse marker $u$-appears without a host in both (18a) (local inverse) and (18b) (mixed inverse), while it is prohibited in (18c) (non-local). The Siyuewu equivalents invariably prohibit the occurence of the inverse marker.

(18) Wobzi Khroskyabs

a. Local inverse

$n \hat{u}=$ yə $\eta \hat{o} \quad u-v d a ́-\eta \eta$

$2 \mathrm{SG}=\mathrm{ERG} 1 \mathrm{sG}$ INV-See $2-1 \mathrm{SG}$

'You saw me.'

b. Mixed inverse

ç̂ = yə nû u-vdé-n

$3 \mathrm{SG}=$ ERG $2 \mathrm{SG}$ INV-See $2-2$

'He saw you.'

c. Non-local

tsacîi= yə tamú vdé

Bkrashis $=$ ERG Lhamo see $_{2}$

'Bkrashis saw Lhamo.'

The negative versions are presented in (19). In local and mixed inverse scenarios, the inverse marker appears alone, preceding the negative marker, as in (19a) and (19b); in non-local scenarios, the inverse marker does not occur, as in (19c). The Siyuewu equivalents have the inverse marker merge with the negative marker in all three cases.

(19) Wobzi Khroskyabs

a. Local inverse

$n \hat{u}=$ ¡ə pô $u-m a-v d a ́-\eta$

$2 \mathrm{SG}=\mathrm{ERG} 1 \mathrm{SG}$ INV-NEG $2-\mathrm{See}_{2}-1 \mathrm{SG}$

'You saw me.'

b. Mixed inverse

$c \hat{s}=$ yə nû u-ma-vdé-n

$3 \mathrm{SG}=\mathrm{ERG} 2 \mathrm{SG}$ INV-NEG $2-\mathrm{See}_{2}-2$

'He saw you.'

c. Non-local

tşaçî̀ tàú ma-vdé

Bkrashis=ERG Lhamo $\mathrm{NEG}_{3}-\mathrm{See}_{2}$

'Bkrashis saw Lhamo.'

Natural examples without orientational prefixes in Wobzi are shown in (20). In (20a), the verb forms $u$-sâ-j (INV-kill $1_{1}-1 \mathrm{PL}$ ) and $u$-dZî-j (INV-eat ${ }_{1}-1 \mathrm{PL}$ ) are employed in a $3 \rightarrow 1$ scenario; in (20b), the inflected verb form mə-nd $\hat{x}\left(\mathrm{NEG}_{1}-\right.$ love $\left._{1}\right)$ is used in a non-local scenario, without inverse.

(20) Wobzi Khroskyabs 
a. Affirmative

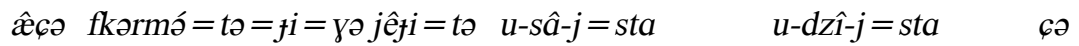

CONJ thief $=$ DEF $=$ PL $=$ ERG 3 PL $=$ DEF INV-kill $l_{1}-1$ PL $=$ PART INV-eat ${ }_{1}-1$ PL $=$ PART CONJ

'The thieves will probably kill us and eat us.' (wob0632)

b. Negative

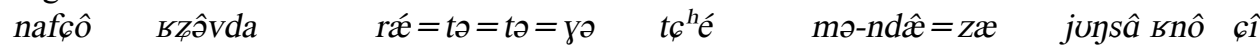

Nag.bsho mountain.deity say $_{1}=\mathrm{DEF}=\mathrm{DEF}=\mathrm{ERG}$ Buddhism $\mathrm{NEG}_{1}$-love ${ }_{1}=\mathrm{CONJ}$ CONJ harm always

$v \hat{i}=p a$

$\mathrm{do}_{1}=\mathrm{NMLZ}$

'The so-called "Nag.bsho mountain deities" do not like Buddhism, and always do harm.' (wob3392)

In Wobzi, non-local scenarios without an orientational prefix do not have inverse morphology, which is unlike Siyuewu that employs the inverse marker in negative forms.

\section{Reconstruction of the Proto-Khroskyabs inverse system}

In this section, I discuss the reason behind the differences of inverse use between the two Khroskyabs varieties, and come up with a hypothesis about the evolution of the inverse marking system in Khroskyabs.

\subsection{Distributions of inverse marking in Siyuewu and Wobzi}

The distributions of inverse marking in the two varieties of Khroskyabs are summarised in Table (7). Scenarios that require inverse marking are shaded. In the cases without an orientational prefix, both affirmative (upper cell) and negative (lower cells) models are given.

Table 7. Inverse distribution in Wobzi and Siyuewu

\begin{tabular}{|c|c|c|c|c|c|c|}
\hline & \multicolumn{3}{|c|}{ Without ORIEN } & \multicolumn{3}{|c|}{ With ORIEN } \\
\hline & Local/mixed inverse & Non-local & Direct & Local/mixed inverse & Non-local & Direct \\
\hline Wobzi & $\begin{array}{c}u-\Sigma \\
u-m a-\Sigma\end{array}$ & $\begin{array}{c}\Sigma \\
m \partial-\Sigma\end{array}$ & $\begin{array}{c}\Sigma \\
m ə-\Sigma\end{array}$ & ORIEN-U- $\Sigma$ & ORIEN $-U-\Sigma$ & ORIEN $-\Sigma$ \\
\hline Siyuewu & $\begin{array}{c}\sum \\
m u-\Sigma\end{array}$ & $\begin{array}{c}\Sigma \\
m u-\Sigma\end{array}$ & $\begin{array}{c}\Sigma \\
m \partial-\Sigma\end{array}$ & ORIEN.INV $-\Sigma$ & ORIEN.INV $-\Sigma$ & ORIEN $-\Sigma$ \\
\hline
\end{tabular}

While the pattern in the presence of an orientational prefix is the same in the two varieties, Wobzi differs from Siyuewu in the non-local configuration in the absence of an orientational prefix. There is no way to say that the Wobzi case is actually inverse. Therefore, Wobzi presents a split in the non-local configuration: inverse in the presence of an orientational prefix, and direct in the absence of an orientational prefix.

To account for the the non-local split in Wobzi Khroskyabs, there are mainly two hypotheses that could be made, listed below.

i Khroskyabs varieties had the double treatment of the non-local configuration attested in Rgyalrong languages, and generalised the inverse treatment to all the cases where an orientational prefix exists, and the direct treatment to all the cases without an orientational prefix; while Siyuewu generalised the inverse treatment to all non-local scenarios regardless of the morphology.

ii Neither Wobzi nor Siyuewu had the double treatment of the non-local configuration attested in Rgyalrong languages, and the difference between the two varieties are due to other factors. 
The first hypothesis is problematic in two ways. First, there is no evidence that the double treatment of the non-local configuration is old, it is unclear whether it can be reconstructed in Proto-West-Rgyalrongic, not to mention Proto-Rgyalrongic; second, even if the double treatment is old and can be reconstructed in Proto-Rgyalrongic, it is problematic from a West-Rgyalrongic point of view. I mentioned in Section 2.3 that the other West-Rgyalrongic subgroup, the Stau varieties also exhibited inverse-generalisation to all nonlocal scenarios. Following the present hypothesis, the inverse-generalisation in Siyuewu would be a parallel innovation alongside the one in the Stau varieties, but not inherited from Proto-West-Rgyalrongic, because Wobzi preserves the direct non-local scenario. Such an evolutionary pathway is surely not the simplest one, and the probability of the parallel innovation is rather low: odds are that the language generalises the direct forms that are simpler than the inverse forms which require an additional marker. The generalisation of the inverse forms can be considered as a typologically uncommon (in Jacques et al. 2017: 609's words, "puzzling") innovation. Given that overwhelming phonological, morphological and lexical evidence points to the close genetic relation between Khroskyabs and Stau (Jacques et al. 2017: 609-611), it is hard not to believe that the inverse-generalisation is a shared innovation of West-Rgyalrongic, rather than an independent development in different sub-branches.

The second hypothesis presumes that the inverse-generalisation is a West-Rgyalrongic innovation, which implies that the direct forms in the non-local configuration in Wobzi is secondary and unrelated to the double treatment in Rgyalrong languages. In the next section, I present this hypothesis in detail.

\subsection{Local inverse and Non-local: the hypothetical prefix * $C ə-$}

In this section, I provisionally focus on the local inverse scenario and the non-local scenario, and leave the discussion on the mixed inverse configuration in Section 5.4.

The present hypothesis is built upon the following presupposition: the non-local inverse-generalisation is inherited from Proto-West-Rgyalrongic, and all that contradicts this generalisation is secondary.

Comparing the distribution of inverse marking in Wobzi and Siyuewu (Table 7), it seems that one can postulate two inverse markers in Proto-Khroskyabs in the case without an orientational prefix, noted ${ }^{*} U_{1}$ - and ${ }^{*} U_{2}$ The first marker, ${ }^{*} U_{1-}$, dropped in both Wobzi and Siyuewu, while the second, ${ }^{*} U_{2}-$, is preserved only in Wobzi as $u$-, and dropped in Siyuewu; the reflexes of ${ }^{*} U_{1}$ - and ${ }^{*} U_{2}$ - with an orientational prefix are the same in the modern language, as shown in (21).

(21) Without ORIEN
a. ${ }^{*} U_{1}->\varnothing$ (Wobzi, Siyuewu)
b. ${ }^{*} U_{2}->u-($ Wobzi), $\varnothing$ (Siyuewu)

Following this reconstruction, the distribution of ${ }^{*} U_{1}$ - and ${ }^{*} U_{2}$ - in Proto-Khroskyabs is shown in Table 8 .

Table 8. Inverse in Proto-Khroskyabs (provisional reconstruction)

\begin{tabular}{c|c|c|c}
\hline & Local & Non-local & Direct \\
\hline Without ORIEN & $* U_{2}-\Sigma$ & $* U_{1}-\Sigma$ & $* \Sigma$ \\
With ORIEN & $*$ ORIEN- $U_{2}-\Sigma$ & $*$ ORIEN- $U_{1}-\Sigma$ & $*$ ORIEN- $\Sigma$ \\
\hline
\end{tabular}

The two inverse markers postulated, ${ }^{*} U_{1}$ - and ${ }^{*} U_{2}$, are without a doubt related to each other. In West Rgyalrongic languages, the inverse marker is in most of the cases dependent on another prefix or a stem. In the case of Khroskyabs varieties, it is usually dependent on the orientational prefixes or the negative prefix, and in Stau varieties, it is totally integrated into the verb stem (Jacques et al. 2014; Gates \& 'ja' dpal manuscript). There is a tendency in which West Rgyalrongic inverse marking requires a host. 
However, it is not necessary to state with absolute certainty that the inverse marking in Proto-Khroskyabs was already dependent on a host. It could be phonologically independent in the beginning, and gradually lost its segmental feature, before finally becoming dependent. After it became dependent, if it is not preceded by any prefix, it cannot occur. If this assumption is valid, the Wobzi inverse $u$-, which can be independent in some cases, must be secondary. I will show in the remainder of the paper that this assumption can tell the story satisfactorily.

I hypothesise that ${ }^{*} U_{2}$, , which left a substantial reflex in Wobzi $(u-)$, was in fact ${ }^{*} U_{1}$ - preceded by a now dropped presyllable, ${ }^{*}$ Cə-, as shown in (22). The presyllable ${ }^{*} \mathrm{C}$ - left almost no trace in modern Khroskyabs varieties, but it provided protection against the dropping of the inverse marker, thus helped preserve this latter in Wobzi. After ${ }^{*} \mathrm{C} ə$ - dropped, the inverse marker was again exposed to the air, which leads to its disappearance in Siyuewu. Now, it is possible to unify ${ }^{*} U_{1}$ - and ${ }^{*} U_{2}$ - into one ${ }^{*} U$-, as shown in (22).

\section{(22) Without ORIEN}

a. Wobzi

$$
{ }^{*} C o-U->{ }^{*} U_{2}->u-
$$

b. Siyuewu

$$
{ }^{*} C ə-U->* U_{2}->(* u-)>\varnothing
$$

The local inverse case with an orientational prefix is reconstructed as *oRIEN-Cə- $U-\Sigma$, symmetrically to the case without an orientational prefix. The non-local case with an orientational prefix is reconstructed as * ORIEN- $U-\Sigma$, without the presyllable * ${ }^{*}$ ə-, symmetrically to its unprefixed counterpart. Both * ORIEN-Cə- $U-\Sigma$ and $*$ ORIEN- $U-\Sigma$ will render the same outcome, ORIEN- $u-\Sigma$ in Wobzi, and orien.Inv- $\Sigma$ in Siyuewu, see (23).

(23) With ORIEN

a. Wobzi ORIEN-Cə- $U-\Sigma>*$ ORIEN- $U-\Sigma>$ ORIEN- $u-\Sigma$

b. Siyuewu ORIEN-Co- $U-\Sigma>*$ ORIEN- $U-\Sigma>$ ORIEN.INV- $\Sigma$

The revised distribution of inverse marking in Proto-Khroskyabs is illustrated in Table 9.

Table 9. Inverse in Proto-Khroskyabs

\begin{tabular}{c|c|c|c}
\hline & Local & Non-local & Direct \\
\hline Without ORIEN & ${ }^{*} C ə-U-\Sigma$ & ${ }^{*} U-\Sigma$ & $* \Sigma$ \\
With ORIEN & $*$ ORIEN-Cə- $U-\Sigma$ & ${ }^{*}$ ORIEN- $U-\Sigma$ & $*$ ORIEN- $\Sigma$ \\
\hline
\end{tabular}

\subsection{Possible origins of $*$ Co-}

The *Co-hypothesis is plausible from the point of view of pure historical linguistics, but comparative evidence is necessary for its solidness, that is, one needs to find out the origin of this ${ }^{*} \mathrm{Co}-$.

According to Table 9, the presyllable occurs in local scenarios (involving first and second persons), but not in the non-local ones (involving third person). It can therefore be postulated that the occurrence of ${ }^{*} \mathrm{C}$ - has to do with SAP arguments: first and/or second persons.

In Rgyalrong languages, the only set of prefixes that can occur in the position of ${ }^{*} \mathrm{Co}$ - are those involving second person: $t V$ - 'second person prefix' and $k V$ - ' $2 \rightarrow 1$ prefix'. The prefix $t V$ - is attested in many other 
“Tibeto-Burman" languages and is probably reconstructible into an even earlier Ursprache (DeLancey 2014) ${ }^{7}$. The generic distribution of these two prefixes in Rgyalrong languages is illustrated in Table 10.

Table 10. Prefixes involving second person in Rgyalrong languages

\begin{tabular}{c|c|c|c|c}
\hline \multicolumn{2}{c|}{} & \multicolumn{3}{c}{$\mathrm{P}$} \\
\cline { 3 - 5 } \multicolumn{2}{c}{} & 1 & 2 & 3 \\
\hline \multirow{3}{*}{$\mathrm{A}$} & 1 & & $t V-$ & \\
\cline { 2 - 5 } & 2 & $k V-$ & & $t V-$ \\
\cline { 2 - 5 } & 3 & & $t V-$ & \\
\hline
\end{tabular}

It can be seen that $t V$-and $k V$-appear in local scenarios, and are absent in non-local scenarios (mixed scenarios are discussed in Section 5.4), which corresponds to the distribution of ${ }^{*} C ə$ - reconstructed for Khroskyabs. I therefore propose that the origin of ${ }^{*} C \partial$ - is related to $t V$ - 'second person prefix' or $k V$ - ' $2 \rightarrow 1$ prefix', or both in Rgyalrong. That Khroskyabs once marked second person prefixally was first proposed by DeLancey (unpublished), in which he states "since we have to reconstruct \#t- for the nearest ancestor of Rgyalrong and South Central Kiranti, other descendants of that ancestor which lack \#t-, such as Khroskyabs and Western Kiranti, must have lost it." Although Zeisler (2015: 40-41) points out a logical inconsistency with Delancey's statement, the inconsistency is irrelevant to the present paper, since, first, I have no intention to discuss the common ancestor of Rgyalrong and Kiranti; second, this paper finds a possible trace of second person marking in Khroskyabs, therefore Khroskyabs probably have not completely lost it.

West-Rgyalrongic languages systematically lost prefixes in $t$ - and $k$-attested in Rgyalrong languages, only some fossilised traces are left. For instance, the indefinite possessive prefix in Rgyalrong, $t V$-, is generally absent in Khroskyabs, see the examples in Table 11. In the first three examples, the Khroskyabs varieties do not present any trace of the indefinite possessive prefix; only the last example probably does, in which the initial $t$ - is fossilised as a part of the noun $\operatorname{stem}^{8}$.

Table 11. The indefinite possessive prefix in Rgyalrong

\begin{tabular}{|c|c|c|c|c|}
\hline Japhug & Bragbar Situ & Siyuewu Khroskyabs & Wobzi Khroskyabs & Gloss \\
\hline tü-jas & ta-jāk & jóy & jáy & hand \\
\hline$t u-r t s^{h} \gamma s$ & tə-rts ${ }^{h} \bar{E} S$ & $r t S^{h} \mathfrak{x} z$ & $r t s^{h} æ ́$ & lung \\
\hline tuu-xtry & $t \partial-k t i \bar{o} k$ & dóy & dáy & brother \\
\hline$t \gamma-\eta k^{h} u t$ & ta-rkū & tyôd & $t v \hat{\partial}$ & fist \\
\hline
\end{tabular}

None of the West-Rgyalrongic languages have the the infinitive prefix $k V$-attested in Rgyalrong languages (Lai 2017: 256), as shown in Table 12. In the last example, the trace of the infinitive prefix, $x$-in Siyuewu and ç- in Wobzi, is preserved as a fossilised part of the verb stem.

\footnotetext{
${ }^{7}$ There is however no consensus regarding the reconstructibility of argument indexation in Trans-Himalayan languages. Some scholars, such as LaPolla (2012) and Zeisler (2015), believe that argument indexation is a recent innovation. I tend to stay neutral with regard to the Trans-Himalayan origin of argument indexation, but I support the view that at least a part of person affixes across Rgyalrongic languages are genetically related.

${ }^{8}$ The phonological condition for the preservation of the indefinite possessive in Khroskyabs is still unknown, as one of the reviewers suggests, although unlikely, the preinitial $t$ - in Khroskyabs could be borrowed from Rgyalrong languages.
} 
Table 12. The infinitive prefix in Rgyalrong

\begin{tabular}{|c|c|c|c|c|}
\hline Japhug & Bragbar Situ & Siyuewu Khroskyabs & Wobzi Khroskyabs & Gloss \\
\hline$k \gamma-p^{h} u t$ & $k a-p^{h} \bar{E} t$ & $p^{h}$ ód & $p^{h} \sigma^{\prime}$ & to cut \\
\hline$k \gamma-n d z a$ & $k a-d z i \hat{\varepsilon}$ & ndzîd & $d z \hat{\imath}$ & to eat \\
\hline$k \gamma-r \not \not i$ & kə-dî & rdôd & $r d \hat{~}$ & to be heavy \\
\hline$k u-f_{s e}$ & kə-psōt & nXsǽV & çnsǽv & to resemble \\
\hline
\end{tabular}

West-Rgyalrongic languages systematically lost the participial prefixes in $k V$-for the relativisation of $\mathrm{S}, \mathrm{A}$ and P, and replaced them with nominalising enclitics (Lai 2018), compare Examples (24) (Japhug) and (25) (Wobzi Khroskyabs). The only trace found in Khroskyabs is in the noun yrêy (Siyuewu)/jrêi (Wobzi) 'superfluous thing', related to réd (Siyuewu)/ré (Wobzi) 'to be left'.

(24) Japhug (Jacques 2016: 7)

a. $k u-s i$

NMLZ:S/A-die

'the dead one'

b. $k \gamma$-sat

NMLZ:P-kill

'The one that is killed'

(25) Wobzi Khroskyabs

a. $n \ni-s \hat{s}=p a$

PST-die ${ }_{2}=$ NMLZ:S

'the dead one'

b. $n-u$-sá $=p a$

PST-INV-kill ${ }_{2}=$ NMLZ:P

'the one that he killed'

Summarising the evidence presented in this section, except for a few fossilised traces, the forms $* t V$ - and ${ }^{*} k V$ - once existed in Khroskyabs, but are generally lost in the modern language. Since the prefixes involving second person in Rgyalrong have exactly the same forms, ${ }^{*} t V$ - and ${ }^{*} k V$-, I assume that they could also have existed in Khroskyabs, and were probably the origins of the ${ }^{*} \mathrm{Co}$ - reconstructed in the present paper. That is to say, ${ }^{*} \mathrm{C}$ - might have two origins, ${ }^{*} \mathrm{k} ə$ - in the $2 \rightarrow 1$ scenario, and ${ }^{*} t ə$ - in other scenarios involving second person, see Table 13.

Table 13. Local scenarios in Proto-Khroskyabs

\begin{tabular}{c|c}
\hline $1 \rightarrow 2$ (Direct) & $2 \rightarrow 1$ (Inverse) \\
\hline${ }^{*} t ə-\Sigma$ & ${ }^{*} k ə-U-\Sigma$ \\
\hline
\end{tabular}

\subsection{Mixed inverse: intra-scenario levelling}

I have discussed the local and non-local cases in the previous sections, and left the mixed configuration untreated. In this section, I focus on the mixed configuration.

The second person origin(s) proposed for ${ }^{*} \mathrm{C} ə$ - is valid for local and non-local scenarios, as ${ }^{*} \mathrm{C} ə$ - does not occur in non-local scenarios involving exclusively third persons. However, when it comes to the mixed configuration, a problem occurs. As shown in Table 14, both $3 \rightarrow 2$ and $3 \rightarrow 1$ scenarios require the inverse marker to occur in Wobzi, which indicates the presence of ${ }^{*} \mathrm{C} ə$ - in both scenarios in Proto-Khroskyabs. Following 
the current hypothesis, the occurrence of ${ }^{*} C$ o- is correctly predicted in $3 \rightarrow 2$, but not in $3 \rightarrow 1$, because the latter scenario does not involve second person.

Table 14. Mixed inverse (without ORIEN)

\begin{tabular}{c|c|c}
\hline & $3 \rightarrow 2$ & $3 \rightarrow 1$ \\
\hline Wobzi & $u-\Sigma$ & $u-\Sigma$ \\
Siyuewu & $\Sigma$ & $\Sigma$ \\
Proto-Khroskyabs & $* C ə-U-\Sigma$ & $* C ə-U-\Sigma ?$ \\
\hline
\end{tabular}

Typologically, it is not impossible for the scenarios $3 \rightarrow 2$ and $3 \rightarrow 1$ to be unified with the same form in TransHimalayan. Jacques (2012a: 94) notices that two of the Kiranti languages, Khaling and Dumi, have the same prefix for the two scenarios in question, $i$ - and a- respectively, and that the prefixes seem to be related to the second person pronouns, in in Khaling and an in Dumi. It can be assumed that in these two languages, the form for $3 \rightarrow 1$ is based on that for $3 \rightarrow 2$. Other Kiranti languags, such as Camling, Bambara and Limbu, distinguish morphologically $3 \rightarrow 2$ from $3 \rightarrow 1$, which shows that the cases of Khaling and Dumi are innovations.

It is possible that Khroskyabs has undergone a similar process as Khaling and Dumi: ${ }^{*} \mathrm{C}$ - was reanalysed as a marker for SAP arguments, and spread from $3 \rightarrow 2$ to $3 \rightarrow 1$, if this process happened in the Proto-Khroskyabs stage. Alternatively, it could be a Wobzi innovation that the prefix $u$ - in the $3 \rightarrow 1$ scenario is based on $3 \rightarrow 2$ due to analogy. Both pathways imply an intra-scenario levelling of the mixed configuration, see (26) for the illustration of the pathways.

(26) Possible pathways of intra-scenario levelling

a. $\quad{ }^{*}$ ¿ə- 'second person marker' $>{ }^{*}$ Cə- 'SAP marker' $>$ Occurrence in $3 \rightarrow 1$

b. Wobzi $u$ - 'INV in scenarios with second person' > Wobzi $u$ - 'INV for local and mixed scenarios' $>$ Occurrence in $3 \rightarrow 1$

\section{Conclusion}

In this paper, I described the functions of inverse marking in two Khroskyabs varieties, Siyuewu and Wobzi, and proposed a hypothesis on the evolution of the inverse marking system in Khroskyabs. A prefix *Co-, probably originally a second person prefix (or maybe two prefixes), is reconstructed to account for the Wobzi $u$ - that appears in the absence of an orientational prefix. It preceded the original inverse marker ${ }^{*} U$-, and dropped in the modern varieties. The modern Wobzi inverse $u$-, is therefore not the original inverse ${ }^{*} U-$, but the trace of the combination of ${ }^{*} \mathrm{Co}$ - and ${ }^{*} U$-, it therefore contains an indirect trace of the second person marker(s). The implication of this hypothesis is that the proto-argument-indexation system is more similar to the Rgyalrong ones than many researchers imagined (such as Jacques 2012a: 93 and DeLancey unpublished), with a whole set of person prefixes (second person markers, inverse) and suffixes.

From Table 15 to Table 18, the development of the system is listed, changes from the previous table are shaded grey. While ${ }^{*} \mathrm{C}$ - is lost everywhere after Proto-Khroskyabs, the proto-inverse-marker ${ }^{*} U$ - dropped step by step when it is hosted by nothing.

Table 15. Stage I: Proto-Khroskyabs

\begin{tabular}{c|ccc}
\hline Orientational prefix & Local inverse & Mixed inverse & Non-local \\
\hline Without & $C ə-U-\Sigma$ & $C ə-U-\Sigma$ & $U-\Sigma$ \\
\hline With & ORIEN-Cə-U- $\Sigma$ & ORIEN-Cə-U- $\Sigma$ & ORIEN- $U-\Sigma$ \\
\hline
\end{tabular}


Table 16. Stage II: Proto-Khroskyabs

\begin{tabular}{c|ccc}
\hline Orientational prefix & Local inverse & Mixed inverse & Non-local \\
\hline Without & $C ə-U-\Sigma$ & $C ə-U-\Sigma$ & $\Sigma$ \\
\hline With & ORIEN-Cə-U- $\Sigma$ & ORIEN-Cə-U- $\Sigma$ & ORIEN- $U-\Sigma$ \\
\hline
\end{tabular}

Table 17. Stage III: Proto-Wobzi

\begin{tabular}{c|ccc}
\hline Orientational prefix & Local inverse & Mixed inverse & Non-local \\
\hline Without & $u-\Sigma$ & $u-\Sigma$ & $\Sigma$ \\
\hline With & ORIEN $-U-\Sigma$ & ORIEN $-U-\Sigma$ & ORIEN- $U-\Sigma$ \\
\hline
\end{tabular}

Table 18. Stage IV: Proto-Siyuewu

\begin{tabular}{c|ccc}
\hline Orientational prefix & Local inverse & Mixed inverse & Non-local \\
\hline Without & $\Sigma$ & $\Sigma$ & $\Sigma$ \\
\hline With & ORIEN- $U-\Sigma$ & ORIEN- $U-\Sigma$ & ORIEN- $U-\Sigma$ \\
\hline
\end{tabular}

\section{References}

DeLancey, Scott. 1981. An interpretation of split ergativity. Language 57(3). 626-57.

DeLancey, Scott. 2014. Second person verb forms in Tibeto-Burman. Linguistics of the Tibeto-Burman Area 37(1). 3-33.

DeLancey, Scott. unpublished. The comparative method, subgrouping, and the antiquity of verb agreement in Trans-Himalayan (Sino-Tibetan).

Gates, Jesse P. \& 'ja' dpal. manuscript. Argument indexation in Stau from a cross-dialectal perspective. URL https://www.academia.edu/35252736/Argument_indexation_in_Stau_from_a_ cross-dialectal_perspective?auto=download.

Gong, Xun. 2014. Personal agreement system of Zbu rGyalrong (Ngyaltsu variety). Transactions of the Philological Society 112(1). 44-60.

Gong, Xun. 2017. Verb stems in Tangut and their orthography. Scripta (9). 29-48.

Gong, Xun. 2018. Le rgyalrong zbu, une langue tibéto-birmane de Chine du Sud-ouest : une étude descriptive, typologique et comparative. Doctoral Dissertation. Institut national des langues et civilation orientales.

Jacques, Guillaume. 2004. Phonologie et morphologie du japhug (Rgyalrong). Doctoral Dissertation. Université Paris VII - Denis Diderot.

Jacques, Guillaume. 2010. The Inverse in Japhug Rgyalrong. Language and Linguistics 11.1. 127-157.

Jacques, Guillaume. 2012a. Agreement morphology: the case of Rgyalrongic and Kiranti. Language and Linguistics 13.1. 83-116.

Jacques, Guillaume. 2012b. Argument demotion in Japhug Rgyalrong. In Haude, Katharina \& Authier, Gilles (eds.), Ergativity, Valency and Voice. 199-226. Berlin: Mouton De Gruyter.

Jacques, Guillaume. 2016. Subjects and objects in Japhug and relativization. Journal of Chinese Linguistics 44(1). 1-28.

Jacques, Guillaume \& Antonov, Anton. 2014. Direct-inverse systems. Language and Linguisitics Compass 8(7). 301-318.

Jacques, Guillaume \& Antonov, Anton \& Lai, Yunfan \& Lobzang, Nima. 2014. Person marking in Stau. Himalayan Linguistics 13(2). 83-93.

Jacques, Guillaume \& Lai, Yunfan \& Antonov, Anton \& Nima, Lobsang. 2017. Stau (Ergong, Horpa). In Thurgood, Graham \& LaPolla, Randy (eds.), The Sino-Tibetan Languages. 597-613. 2nd edn. Abingdon and New York: Routledge. 
Klaiman, M.H. 1992. Inverse languages. Lingua 88.3/4. 227-261.

Lai, Yunfan. 2015. The Person Agreement System of Wobzi Lavrung (rGyalrongic, Tibeto-burman). Transactions of the Philological Society 113(3). 271-285.

Lai, Yunfan. 2017. Grammaire du khroskyabs de wobzi. Doctoral Dissertation. Université Paris 3 - Sorbonne Nouvelle.

Lai, Yunfan. 2018. Relativisation in Wobzi Khroskyabs and the integration of genitivisation. Linguistics of the Tibeto-Burman Area 41(2). 219-262.

Lai, Yunfan \& Gong, Xun \& Gates, Jesse P. \& Jacques, Guillaume. manuscript. Tangut as a West Rgyalrongic language.

LaPolla, Randy. 2012. Comments on Methodology and Evidence in Sino-Tibetan Comparative Linguistics. Language and Linguistics 13.1. 117-132.

Sagart, Laurent \& Jacques, Guillaume \& Lai, Yunfan \& Ryder, Robin J. \& Thouzeau, Valentin \& Greenhill, Simon J. \& List, Johann-Mattis. 2019. Dated language phylogenies shed light on the ancestry of sinotibetan. Proceedings of the National Academy of Sciences 116(21). 10317-10322. URL https://www . pnas.org/content/116/21/10317.

Sun, Jackson T.-S. 2000a. Parallelisms in the Verb Morphology of Sidaba rGyalrong and Lavrung in rGyalrongic. Language and Linguistics 1(1). 161-190.

Sun, Jackson T.-S. 2000b. Stem Alternations in Puxi Verb Inflection: Toward Validating the rGyalrongic Subgroup in Qiangic. Language and Linguistics 1(2). 211-232.

Sun, Jackson T.-S. 2015. 黑水縣沙石多嘉戎語動詞人稱範疇的特點. Language and Linguisitics 16(5). 731-750.

Sun, Jackson T.-S. \& Tian, Qianzi. 2014. 霍爾語格西話動詞對協初探. 中國語言學集刊 7(2). 203-223.

Wolfart, H. C. \& Carroll, J. F. 1981. Meet Cree: A practical guide to the Cree language. 2nd edn. Edmonton: University of Alberta Press.

Wolfart, H. Christoph. 1973. Plains Cree: A Grammatical Study. Transactions of the American Philosophical Society 63.5. 1-90.

Wylie, Turrel. 1959. A standard system of Tibetan transcription. Havard Journal of Asiatic Studies 261-267.

Zeisler, Bettina. 2015. Eat and drink - if you can! A language internal explanation for the 'irregular' paradigm of Tibetan za, zos, zo 'eat'. Himalayan Linguistics 15(1). 34-62.

Zhang, Shuya. 2019. From proximate/obviative to number marking: Reanalysis of hierarchical indexation in Rgyalrong languages. Journal of Chinese Linguistics 47(1). 125-150.

Zúñiga, Fernando. 2006. Deixis and Alignment - Inverse systems in indigenous languages of the Americas. Amsterdam: Benjamins. 